C04

\title{
Fault Reactivation and Fault Properties - 3D Geomechanical Modeling Approach and Application to Nuclear Waste Disposal
}

\author{
L. Maerten* (IGEOSS), R. Soliva (University Montpellier), F. Maerten \\ (IGEOSS), I. Aaltonen (Posiva Oy), L. Wilkström (Posiva Oy) \& J. Mattila \\ (Geological Survey of Finland)
}

\section{SUMMARY}

We present the preliminary results of a methodology that consists on modeling $3 \mathrm{D}$ fault reactivation and to relate both the computed fault slip and residual stresses to fault seal and leakage capacity. A series of geomechanical simulations is run on a 3D fault model, which integrates friction, cohesion, far field stress and fluid pressure as variables. The hundreds of simulations are analyzed as a whole in order to determine the likelihood of fault reactivation with respect to the variable parameters. Each reactivated fault is then analyzed independently. Fault sealing and/or leakage capacity can be estimated when the relationship between computed fault slip and/or residual stresses and fault zone deformation mechanisms is known. The methodology has been applied and tested on the Olkiluoto nuclear waste repository site, Finland. The method can be applied to petroleum reservoirs, where depletion can affects fault reactivation, hence fault sealing and leakage reliability. 


\section{Fault and Top Seals \\ Montpellier 2009}

\section{Introduction}

Fault sealing and leakage are key parameters for both nuclear waste disposal and exploitation of natural resources. These parameters are related to mechanism of deformation that change in space along the fault planes and through time as the overall deformation of the subsurface area evolves. The challenging methodology described in this contribution aims at relating computed fault reactivation (i.e. fault slip and residual stresses) to potential fault sealing and/or leakage through time. As a test case, we use the fast 3D boundary element code Poly3D (Thomas 1993; Maerten et al. 2005) from IGEOSS, for modeling fault reactivation in the Olkiluoto nuclear waste repository site, Finland.

\section{Methodology}

The methodology can be resumed as follow:

1. Building of 3D fault model that must be as close as possible to the geological reality. Faults are triangulated surfaces suited for Poly3D;

2. Setting the constant parameters such as the rock type and half space options;

3. Setting the fault variable parameters that can be friction, cohesion and fluid pressure;

4. Setting the 3D far field stress as a variable. This far field stress coming tectonic forces or ice load can be heterogeneous (i.e. gradients);

5. Run of hundreds of simulations with varying parameters;

6. Global automatic analyzes of the results (i.e. 3D graph) in order to evaluate which combinations of parameters lead to fault reactivation;

7. Spatial analyzes of the results looking at individual fault that have been reactivated (i.e. slip and residual stresses);

8. Establish a relationship between fault slip or residual stresses and deformation mechanisms in order to infer fault seal and leakage capacity.

\section{Example case study}

The Olkiluotto repository site is located in faulted and fractured gneisses, which has been deformed during several tectonic phases (Andersson et al. 2007). These tectonic deformations allowed the formation of interacting and intersecting ductile thrust faults formed at depth. These deformation zones were exhumed and reactivated during late extensional and compressional events in a more brittle context. Kilometre scale brittle deformation zones therefore formed during poly phased tectonic events and are subjected to be reactivated in the future during glacial loading and unloading cycles.

\section{Model configuration}

The 3D model geometry has been build from surface mapping, well bore, tunnels and seismic reflection data. It includes 10 intersecting thrust faults with dip angles varying from 30 to 70 degrees (see Fig. 1a).
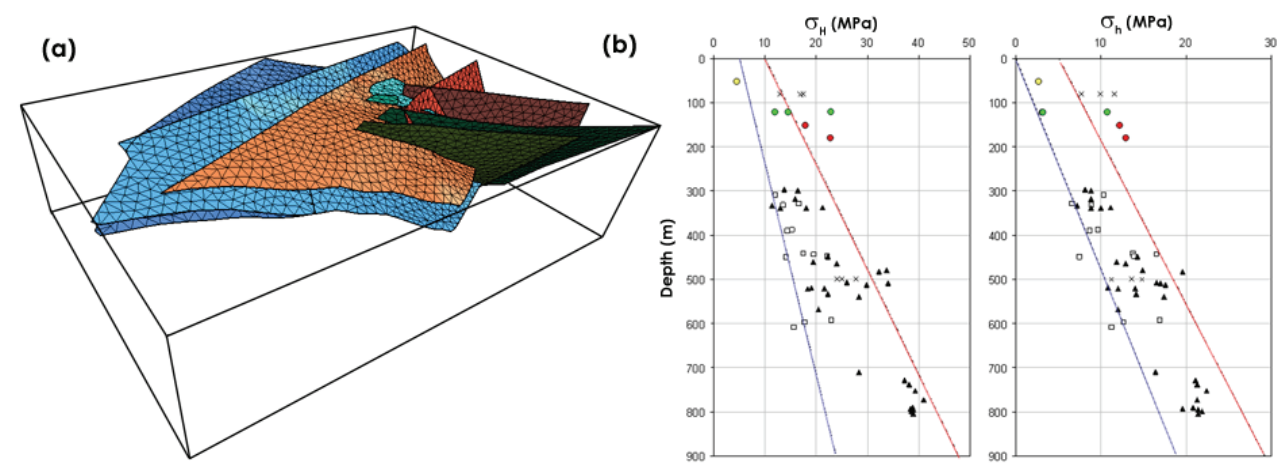

Figure 1 Model configuration. (a) 3D fault model as triangulated surfaces and (b) measured in-situ stresses used as a base for the far field stress boundary conditions. 


\section{Fault and Top Seals \\ Montpellier 2009}

Since the aim is to model the effect of a vertical ice sheet, the principal parameter to use as a variable is the applied state of stress, which is strongly dependent on the thickness of the mass above the faults (see Fig. 1b). Extrapolating the present stresses to the future (i.e. $115000 \mathrm{yr}$ ) and with the addition of a variable ice sheet thickness, a resulting stress gradients can be calculated and applied to the model. Data derived from in situ bore hole measurements and rock tests were provided and used as constant (i.e. elastic moduli) or variable (i.e. cohesion, friction) parameters in this preliminary study (Hudson and Johansson 2006).

\section{Model results analysis}

A total of 1331 Poly3D simulations have been run using the far filed stresses, the friction and the cohesion as variables. Each run in which at least one triangular element of the fault surfaces has slipped is identified as a "slipping model". The runs, in which no triangular element has slipped is identified as "non slipping models". Figure 2a and b shows 3D graphs illustrating slipping and non slipping models as 3D fields separated by a rupture envelope, which is function of friction, cohesion and ice thickness.
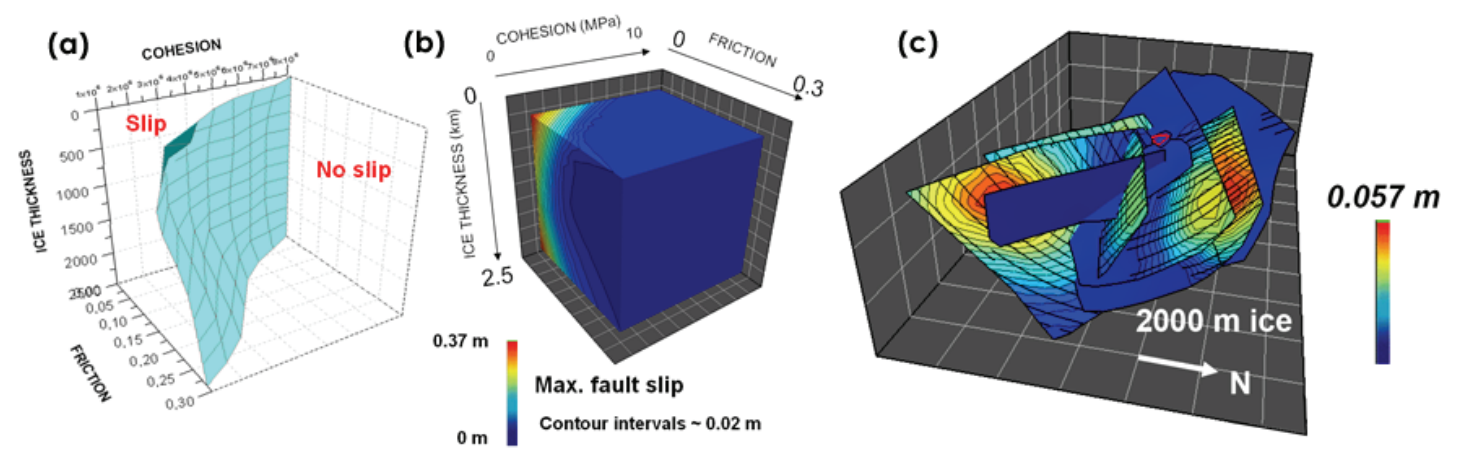

Figure 2 Model results. (a) 3D rupture envelope. (b) Iso-surfaces of maximum slip for the entire model. (c) Fault slip distribution computed for $2000 \mathrm{~m}$ of ice, a friction of 0.085 and a cohesion of $2 \mathrm{MPa}$.

Figure 2c illustrates how individual run can be analyzed. Here fault slip distribution is displayed with slip vectors. Only some zone of the faults have slipped in response too fault mechanical interaction, friction, cohesion and far field stress.

\section{Conclusion}

The preliminary results of the methodology presented here appear promising. The methodology aims at relating computed slip or residual stress along reactivated faults with fault sealing and leakage capacity. The methodology has been applied and tested on the Olkiluoto nuclear waste repository site, Finland but could be applied to petroleum reservoirs, where depletion can affects fault reactivation, hence fault leakage.

\section{References}

Andersson, J., Ahokas, H., Hudson, J., Koskinen, L., Luukkonen, A., Löfman, J., Keto, V., Pitkänen, P., Mattila, J., Ikonen, A.T.K. and Ylä-Mella, M. [2007] Olkiluoto Site Description, Part 1. Posiva report 2007-3.

Hudson, J. A. and Johansson, E. [2006] Summary of Rock Mechanics Work Completed for Posiva before 2005, Posiva report 2006-4.

Maerten, F., Resor, P. G., Pollard, D. D. and Maerten, L. [2005] Inverting for Slip on ThreeDimensional Fault Surfaces using Angular Dislocations: Bulletin of the Seismological Society of America, v. 95, p. 1654-1665.

Thomas, A. L. [1993] Poly3d: a three-dimensional, polygonal element, displacement discontinuity boundary element computer program with applications to fractures, faults, and cavities in the Earth's crust: Master thesis, Stanford University, Stanford, California, U.S.A., p. 69. 